\title{
Sperm penetration in vitro of human oocytes matured in a chemically defined medium*
}

\author{
T. Nishimoto $\dagger$, I. Yamada $\uparrow$, K. Niwa, T. Mori†, T. Nishimura $\dagger$ and \\ A. Iritani \\ Department of Animal Science, College of Agriculture, and $\dagger$ Department of Obstetrics and \\ Gynaecology, School of Medicine, Kyoto University, Kyoto 606, Japan
}

\begin{abstract}
Summary. Human oocytes were obtained randomly from the ovaries excised from 28 patients at different stages of the menstrual cycle. When 114 oocytes were cultured for $40-40.5 \mathrm{~h}$ in a chemically defined medium, 80 showed degeneration. When 16 of the remaining 64 oocytes were examined for their maturation, germinal vesicle breakdown (GVBD) had occurred in 11 oocytes. Another 48 oocytes were inseminated by ejaculated spermatozoa which were washed twice and preincubated for $3 \mathrm{~h}$. When examined $10 \mathrm{~h}$ later, $19(39.6 \%)$ were penetrated with an enlarged sperm head or male pronucleus(ei) and its corresponding sperm tail(s).
\end{abstract}

\section{Introduction}

Since the first observation of nuclear maturation (Pincus \& Saunders, 1939) and fertilization (Edwards, Bavister \& Steptoe, 1969) of human oocytes cultured in vitro, various media with different chemical compositions have been used for these purposes (see Kennedy, 1972, for review). Although clear cytological evidence of in-vitro fertilization of human oocytes matured in various media containing human follicular fluid has been reported (Edwards et al., 1969; Bavister, Edwards \& Steptoe, 1969; Soupart \& Morgenstern, 1973), there is no presently available single system for the successful maturation and sperm penetration in vitro of human oocytes. This paper reports such a system.

\section{Materials and Methods}

The medium used for manipulation of gametes was a modified Krebs-Ringer-bicarbonate solution (modified KRB containing $94.6 \mathrm{mM}-\mathrm{NaCl}, 4.78 \mathrm{mM}-\mathrm{KCl}, 1.71 \mathrm{mM}-\mathrm{CaCl}_{2}, 1.19$ mM- $\mathrm{KH}_{2} \mathrm{PO}_{4}, 1.19 \mathrm{~mm}-\mathrm{MgSO}_{4}, 25.07 \mathrm{mM}-\mathrm{NaHCO}_{3}, 21.58 \mathrm{~mm}$-sodium lactate, $0.5 \mathrm{~mm}$ sodium pyruvate, $5.56 \mathrm{~mm}$-glucose, $4 \mathrm{mg}$ crystalline bovine serum albumin (Sigma Chemical Co.) $/ \mathrm{ml}, 50 \mu \mathrm{g}$ streptomycin sulphate $/ \mathrm{ml}$ and $75 \mu \mathrm{g}$ potassium penicillin $/ \mathrm{ml}$ ).

The ovaries were excised from 28 patients, 30-43 years of age, undergoing laparotomy at different stages of the menstrual cycle for various gynaecological indications such as myoma uteri and carcinoma. The ovaries recovered on Days 1-12,13-15 and 16-37 of the cycle (onset of menstruation Day 1) were considered as being from women at the follicular, ovulatory and luteal phases, respectively. The oocytes were collected by randomly puncturing follicles within 2 $\mathrm{h}$ after removal. The collected oocytes were evaluated under a dissecting microscope; those with

* Reprint requests to Dr A. Iritani. 
non-homogeneous and/or shrunken vitellus (about 30\%) and those with sparse or absent follicular cells (about 10\%) were considered degenerate and were not used for culture. Although the normality of the vitellus was not assessed in some oocytes with several compact layers of corona radiata cells, such oocytes were used for culture on the assumption that they were normal. Thus, 1-17 oocytes were obtained from an ovary. After washing twice with the medium, 1-3 oocytes were introduced into $0.4 \mathrm{ml} \mathrm{m}$-KRB solution covered with warm paraffin oil in a plastic culture dish $(35 \times 11 \mathrm{~mm})$ and cultured for $40-40.5 \mathrm{~h}$ in a $\mathrm{CO}_{2}$ incubator $\left(5 \% \mathrm{CO}_{2}\right.$ in air at $37^{\circ} \mathrm{C}$ ). After the end of culture, the oocytes were again simply observed under a dissecting microscope and those showing clear cytoplasmic degeneration were excluded. Some of the oocytes for which it was difficult to observe the vitellus were picked out and examined for the stages of maturation after mechanical removal of the follicular cells. The remaining oocytes including those in which an extruded polar body was observed were washed twice and exposed to preincubated spermatozoa.

Semen specimens were obtained from healthy fertile donors. After spontaneous liquefaction at $30-37^{\circ} \mathrm{C}, 2-3 \mathrm{ml}$ of the medium were added and the diluted semen was centrifuged at $30 \mathrm{~g}$ for $10 \mathrm{~min}$ to remove coarse particles. Spermatozoa in the supernatant were then washed twice by centrifugation at $300 \mathrm{~g}$ for $10 \mathrm{~min}$ and finally resuspended in $2 \mathrm{ml} \mathrm{m}$-KRB solution. A portion $(20-40 \mu \mathrm{l})$ of the sperm suspension was introduced into $0.4 \mathrm{ml} \mathrm{m}$-KRB solution which was covered with warm paraffin oil in a plastic culture dish $(35 \times 11 \mathrm{~mm})$. The diluted sperm suspension containing $0.5-1.0 \times 10^{6}$ spermatozoa $/ \mathrm{ml}$ was preincubated for $3 \mathrm{~h}$ in a $\mathrm{CO}_{2}$ incubator. After the cultured oocytes had been incubated with the spermatozoa for $10 \mathrm{~h}$, the oocytes were examined for evidence of sperm penetration.

Throughout the present study, the oocytes were mounted in toto, and were then fixed with $2.5 \%$ glutaraldehyde and $10 \%$ neutral formalin and stained with $0.25 \%$ lacmoid in $45 \%$ acetic acid. They were examined to determine the stages of maturation and for evidence of sperm penetration. The term 'matured' was used for oocytes with an extruded first polar body in the perivitelline space and a second metaphase plate of chromosomes within the vitellus. The term 'penetrated' was used for oocytes with an enlarged sperm head or male pronucleus(ei) with their corresponding sperm tail(s) in the vitellus.

\section{Results}

As shown in Table 1, over half of the oocytes showed cytoplasmic degeneration after culture for $40-40.5 \mathrm{~h}$. When 16 of the remaining oocytes were examined for their maturation, 6 had reached metaphase of the second meiotic division extruding the first polar body (Pl. 1, Fig. 1), 5 were at the germinal vesicle stage or degenerated, and another 5 were at metaphase of the first

Table 1. Maturation in culture of human oocytes in a chemically defined medium

\begin{tabular}{|c|c|c|c|c|c|c|c|c|}
\hline \multirow{3}{*}{$\begin{array}{l}\text { Menstrual } \\
\text { cycle } \\
\text { (days) }\end{array}$} & \multirow{3}{*}{$\begin{array}{c}\text { No. of } \\
\text { patients }\end{array}$} & \multicolumn{4}{|c|}{ No. of oocytes } & \multirow{2}{*}{\multicolumn{2}{|c|}{$\begin{array}{l}\text { No. of immature } \\
\text { oocytes at the } \\
\text { stage of: }\end{array}$}} & \multirow{3}{*}{$\begin{array}{c}\text { No. of } \\
\text { oocytes } \\
\text { inseminated }\end{array}$} \\
\hline & & & \multirow{2}{*}{$\begin{array}{c}\text { Showing cytoplasmic } \\
\text { degeneration after } \\
\text { culture }(\%)\end{array}$} & \multirow[b]{2}{*}{ Examined* } & \multirow{2}{*}{$\begin{array}{c}\text { Matured } \\
\text { to MII } \\
(\%)\end{array}$} & & & \\
\hline & & Cultured & & & & GV/Deg. & MI & \\
\hline $1-12$ & 11 & 55 & $22(40 \cdot 0)$ & 9 & $3(33 \cdot 3)$ & 3 & 3 & 24 \\
\hline $13-15$ & 6 & 29 & $18(64 \cdot 3)$ & 3 & $1(33 \cdot 3)$ & 1 & 1 & 8 \\
\hline $16-37$ & 11 & 60 & $40(66 \cdot 7)$ & 4 & $2(50.0)$ & 1 & 1 & 16 \\
\hline Total & 28 & 144 & $80(55.9)$ & 16 & $6(37 \cdot 5)$ & 5 & 5 & 48 \\
\hline
\end{tabular}

GV/Deg., germinal vesicle or degenerating; MI, MII, metaphase of the first and second meiotic divisions.

* Oocytes showing cytoplasmic degeneration under a dissecting microscope $40 \mathrm{~h}$ after culture were not used for examination of maturity or for insemination. 

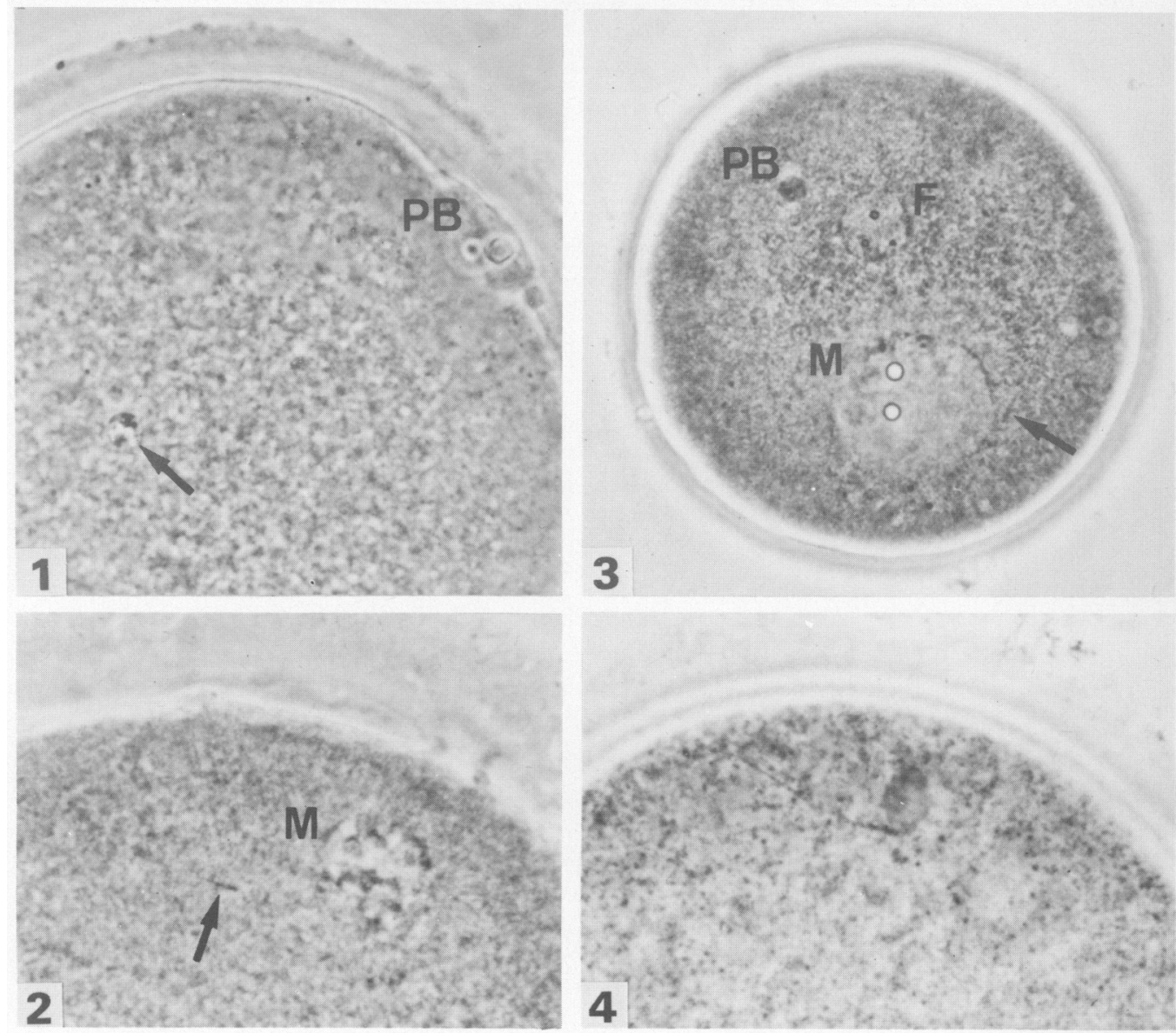

Fig. 1. An oocyte at the metaphase of the second meiotic division fixed $40 \mathrm{~h}$ after culture, showing first polar body (PB) and a metaphase plate of chromosomes (arrow). Although the metaphase plate is usually much nearer the extruded polar body, the separation in this figure is not exceptional. $\times 510$.

Fig. 2. An egg at the pronuclear stage fixed $10 \mathrm{~h}$ after additional culture with spermatozoa preincubated for $3 \mathrm{~h}$, showing the sperm midpiece (arrow) in close association with the male pronucleus $(\mathrm{M}) . \times 510$.

Fig. 3. An egg at the pronuclear stage fixed $10 \mathrm{~h}$ after additional culture with spermatozoa preincubated for $3 \mathrm{~h}$, showing the male pronucleus $(\mathrm{M})$, the female pronucleus $(\mathrm{F})$, the second polar body (PB) and the sperm midpiece (arrow). $\times 350$.

Fig. 4. The fertilizing spermatozoon in an oocyte fixed $10 \mathrm{~h}$ after additional culture with spermatozoa preincubated for $3 \mathrm{~h}$, showing the beginning of nuclear swelling. $\times 510$.

(Facing p. 116) 
meiotic division. Normal germinal vesicle breakdown (GVBD) therefore occurred in $6 / 9,2 / 3$ and $3 / 4$ of the oocytes obtained from the ovaries at the follicular, ovulatory and luteal phases, respectively.

When the remaining oocytes were introduced into the preincubated spermatozoa and examined $10 \mathrm{~h}$ later, $6 / 8$ of the oocytes from the ovaries at the ovulatory phase were penetrated (Table 2). A lower proportion of the oocytes from the ovaries at the other stages of the cycle were penetrated, and a significant difference $(P<0.02)$ was found between the values for follicular and ovulatory phases. The details of the conditions of penetrated and unpenetrated oocytes are summarized in Table 2 . About $74 \%$ of the oocytes penetrated were at the pronuclear stage with male and female pronuclei, penetrating sperm tail(s) and two polar bodies (Pl. 1, Figs 2 and 3). Penetration with an enlarged sperm head (Pl. 1, Fig. 4) was observed in 5 oocytes which were still at metaphase of the first meiotic division.

Table 2. Conditions of penetrated and unpenetrated oocytes $10 \mathrm{~h}$ after insemination

\begin{tabular}{|c|c|c|c|c|c|c|c|}
\hline \multirow{3}{*}{$\begin{array}{c}\text { Menstrual } \\
\text { cycle } \\
\text { (days) }\end{array}$} & \multirow{3}{*}{$\begin{array}{c}\text { No. of } \\
\text { oocytes } \\
\text { inseminated }\end{array}$} & \multicolumn{3}{|c|}{ No. of oocytes penetrated } & \multirow{2}{*}{\multicolumn{3}{|c|}{$\begin{array}{l}\text { No. of unpenetrated oocytes } \\
\text { at the stage of: }\end{array}$}} \\
\hline & & \multirow[b]{2}{*}{$\begin{array}{c}\text { Total } \\
(\%)\end{array}$} & \multirow{2}{*}{$\begin{array}{l}\text { With enlarged } \\
\text { sperm head } \\
\text { but without } \\
\text { polar bodies } \dagger\end{array}$} & \multirow{2}{*}{$\begin{array}{l}\text { With male } \\
\text { and female } \\
\text { pronuclei }\end{array}$} & & & \\
\hline & & & & & GV/Deg. & MI & $\begin{array}{c}\text { MII } \\
\text { (with PB 1) }\end{array}$ \\
\hline $1-12$ & 24 & $6(25 \cdot 0)^{*}$ & 1 & $5 \S$ & 10 & 6 & 2 \\
\hline $13-15$ & 8 & $6(75 \cdot 0)^{*}$ & 2 & 4 & 0 & 2 & 0 \\
\hline $16-37$ & 16 & $7(43 \cdot 8)$ & 2 & 5 & 5 & 3 & 1 \\
\hline Total & 48 & $19(39 \cdot 6)$ & 5 & 14 & 15 & 11 & 3 \\
\hline
\end{tabular}

GV/Deg., germinal vesicle or degenerating; MI, MII, metaphase of first and second meiotic divisions; PB1, first polar body.

* Significantly different $\left(P<0.02 ; \chi^{2}\right.$ test $)$.

+ With the exception of one oocyte which had indistinct female chromatin, all the other oocytes were at metaphase of first meiotic division.

¥First and second polar bodies, and penetrating sperm tail(s) were clearly recognized in these oocytes.

$\S$ One oocyte had 2 male pronuclei and their corresponding sperm tails.

The total culture period for the oocytes was $50-50.5 \mathrm{~h}(40-40.5 \mathrm{~h}$ alone and $10 \mathrm{~h}$ with spermatozoa) and normal GVBD occurred in $44(30.6 \%)$ of 144 oocytes cultured and of these 23 oocytes reached metaphase of the second meiotic division (Tables 1 and 2).

\section{Discussion}

Maturation of rat (Niwa \& Chang, 1975), cow (Iritani \& Niwa, 1977) and pig (Iritani, Niwa \& Imai, 1978) follicular oocytes followed by successful sperm penetration in vitro has been achieved in a m-KRB solution which was suitable for in-vitro fertilization of rat (Toyoda \& Chang, 1974; Niwa \& Chang, 1975), hamster and mouse (Niwa, Imai, Kim \& Iritani, 1980) eggs. In the present study, human follicular oocytes also matured in this medium followed by successful penetration in vitro by preincubated spermatozoa.

When the oocytes showing cytoplasmic degeneration $40-40.5 \mathrm{~h}$ after culture were excluded after microscopic observation, $11(68.8 \%)$ of the 16 oocytes examined underwent GVBD reaching metaphase of the first or second meiotic division (Table 1). These figures are comparable to those obtained by Kennedy \& Donahue (1969), who found that $50 \cdot 0-63.2 \%$ of human oocytes cultured for $43-47 \mathrm{~h}$ in the defined F10 medium reached metaphase of the first or second meiotic division. However, Kennedy \& Donahue (1969) used all of the oocytes recovered from the ovary for culture and did not exclude those obviously degenerated after 
culture, and it is therefore considered that the actual maturation rate obtained in the present study may be lower than their figures. Although we tried to exclude the degenerated oocytes from culture, the proportion of oocytes undergoing GVBD after culture was reduced to $30.6 \%$ (Tables 1 and 2). This lower percentage of the oocytes undergoing GVBD in the present study compared with that reported by Kennedy \& Donahue (1969) may be partly due to differences in the composition of the medium used. Furthermore, since it seems that the oocytes showing degeneration before culture would not mature in subsequent culture, the initial selection of the oocytes for culture may affect the percentage of those matured.

Penetration rate of human oocytes following maturation in culture is generally low. Edwards et al. (1969) reported that only 7 of 34 oocytes matured in culture for $38 \mathrm{~h}$ were penetrated with male and female pronuclei. Soupart \& Morgenstern (1973) reported that the presence of FSH, $\mathrm{LH}$ and hCG in the medium resulted in a highly significant increase in sperm penetration of the oocytes matured in vitro, but that only 1 of 20 oocytes inseminated in the presence of hormones was penetrated with pronuclei. In the present study, $19(39.6 \%)$ of the 48 oocytes used after culture for 40-40.5 h were penetrated with an enlarged sperm head or pronuclei in their vitelli 10 $\mathrm{h}$ after insemination with preincubated spermatozoa (Tables 1 and 2; Pl. 1, Figs 2,3 and 4). Lopata, McMaster, McBain \& Johnston (1978) reported that human spermatozoa may become capacitated in vitro in a chemically defined medium, which has very similar constituents to those in the $\mathrm{m}-\mathrm{KRB}$ solution. Although we did not examine the exact time of sperm penetration, it appears that capacitation of human spermatozoa is completed during the $3-\mathrm{h}$ preincubation in $\mathrm{m}-\mathrm{KRB}$ solution and/or during the $10 \mathrm{~h}$ incubation with the oocytes. The significantly lower penetration rate $(25.0 \%)$ in the oocytes from ovaries at the follicular phase than from those at the ovulatory phase $(75.0 \%)$ is unexplained at present. However, it may be suggested that the oocytes from mid-cycle ovaries were more likely to have been exposed to LH in vivo prior to recovery, and were therefore capable of full maturation in vitro followed by superior sperm penetration.

From the observations of the penetrated and unpenetrated oocytes at $10 \mathrm{~h}$ after insemination, it is considered that normal GVBD had occurred, reaching metaphase of the first or second meiotic division, in 33 of 48 oocytes at insemination (Table 2). Since 19 (57.6\%) of these 33 oocytes were penetrated, it appears that the oocytes normally maturing in culture are easily penetrated by spermatozoa preincubated in the present system. However, it is suggested that penetrated oocytes undergoing normal fertilization can be obtained only in those matured to metaphase of the second meiotic division, because the sperm heads penetrating oocytes at metaphase of the first meiotic division underwent swelling but did not transform to the pronucleus. Similar findings have been reported for mouse (Iwamatsu \& Chang, 1972) and rat (Niwa \& Chang, 1975) oocytes. The maturation of ooplasm as a whole, therefore, could be of importance for normal fertilization.

We thank Dr R. Nakamura of Kyoto National Hospital for supplying the ovaries. This work was supported by grants from the Ford Foundation (No. 740-0404) and the Ministry of Education of Japan. T.M. is a recipient of W.H.O. grant No. 77/66.

\section{References}

Bavister, B.D., Edwards, R.G. \& Steptoe, P.C. (1969) Identification of the midpiece and tail of the spermatozoa during fertilization of human eggs in vitro. J. Reprod. Fert. 20, 159-160.

Edwards, R.G., Bavister, B.D. \& Steptoe, P.C. (1969) Early stages of fertilization in vitro of human oocytes matured in vitro. Nature, Lond. 221, 632-635.
Iritani, A. \& Niwa, K. (1977) Capacitation of bull spermatozoa and fertilization in vitro of cattle follicular oocytes matured in culture. J. Reprod. Fert. 50, 119-121.

Iritani, A., Niwa, K. \& Imai, H. (1978) Sperm penetration in vitro of pig follicular oocytes matured in culture. J. Reprod. Fert. 54, 379-383. 
Iwamatsu, T. \& Chang, M.C. (1972) Sperm penetration in vitro of mouse oocytes at various times during maturation. J. Reprod. Fert. 31, 237-247.

Kennedy, J.F. (1972) Maturation and fertilization of human oocytes in vitro. In Oogenesis, pp. 439-457. Eds J. D. Biggers \& A. W. Schuetz. University Park Press, Baltimore.

Kennedy, J.F. \& Donahue, R.P. (1969) Human oocytes: maturation in a chemically defined medium. Science, N.Y. 164, 1292-1293.

Lopata, A., McMaster, R., McBain, J.C. \& Johnston, W.I.H. (1978) In-vitro fertilization of preovulatory human eggs. J. Reprod. Fert. 52, 339-342.

Niwa, K. \& Chang, M.C. (1975) Fertilization of rat eggs in vitro at various times after ovulation with special reference to fertilization of ovarian oocytes matured in culture. J. Reprod. Fert. 43, 435-451.
Niwa, K., Imai, H., Kim, C.I. \& Iritani, A. (1980) Fertilization in vitro of hamster and mouse eggs in a chemically defined medium. J. Reprod. Fert. 58, 109-114.

Pincus, G. \& Saunders, B. (1939) The comparative behavior of mammalian eggs in vivo and in vitro. IV. The maturation of human ovarian ova. Anat. Rec. 75, 537-545.

Soupart, P. \& Morgenstern, L.L. (1973) Human sperm capacitation and in vitro fertilization. Fert. Steril. 24, $462-478$.

Toyoda, Y. \& Chang, M.C. (1974) Fertilization of rat eggs in vitro by epididymal spermatozoa and development of the eggs following transfer. $J$. Reprod. Fert. 36, 9-22.

Received 25 March 1981 